\title{
Socioeconomic and geographic variations in antenatal care coverage in Angola: further analysis of the 2015 demographic and health survey
}

Gebretsadik Shibre', Betregiorgis Zegeye ${ }^{2}$, Dina Idriss-Wheeler ${ }^{3}$, Bright Opoku Ahinkorah", Olanrewaju Oladimeji ${ }^{5,6,7}$ and Sanni Yaya ${ }^{8,9^{*}}$ [D

\begin{abstract}
Background: In African countries, including Angola, antenatal care (ANC) coverage is suboptimal and maternal mortality is still high due to pregnancy and childbirth-related complications. There is evidence of disparities in the uptake of ANC services, however, little is known about both the socio-economic and geographic-based disparity in the use of ANC services in Angola. The aim of this study was to assess the extent of socio-economic, urban-rural and subnational inequality in ANC coverage in Angola.

Methods: We analyzed data from the 2015 Angola Demographic and Health Survey (ADHS) using the World Health Organization (WHO) Health Equity Assessment Toolkit (HEAT) software. The analysis consisted of disaggregated ANC coverage rates using four equity stratifiers (economic status, education, residence, and region) and four summary measures (Difference, Population Attributable Risk, Ratio and Population Attributable Fraction). To measure statistical significance, an uncertainty interval (UI) of 95\% was constructed around point estimates.

Results: The study showed both absolute and relative inequalities in coverage of ANC services in Angola. More specifically, inequality favored women who were rich $(D=54.2,95 \% \mathrm{UI} ; 49.59,58.70, \mathrm{PAF}=43.5,95 \% \mathrm{UI} ; 40.12$, 46.92), educated (PAR $=19.9,95 \% \mathrm{UI} ; 18.14,21.64, R=2.14,95 \% \mathrm{UI} ; 1.96,2.32)$, living in regions such as $L$ uanda $(\mathrm{D}=$ $51.7,95 \% \mathrm{UI} ; 43.56,59.85, R=2.64,95 \% \mathrm{UI} ; 2.01,3.26$ ) and residing in urban dwellings (PAF $=20,95 \% \mathrm{UI} ; 17.70$, 22.38, PAR $=12.3,95 \% \mathrm{UI} ; 10.88,13.75)$.

Conclusion: The uptake of ANC services were lower among poor, uneducated, and rural residents as well as women from the Cuanza Sul region. Government policy makers must consider vulnerable subpopulations when designing needed interventions to improve ANC coverage in Angola to achieve the 2030 Sustainable Development Goal of reducing global maternal mortality ratio to 70 deaths per 100,000 live births.
\end{abstract}

Keywords: Antenatal care, Inequality, Health disparities, Global health; Angola, DHS

\footnotetext{
* Correspondence: sanni.yaya@uOttawa.ca

${ }^{8}$ School of International Development and Global Studies, Faculty of Social Sciences, University of Ottawa, 120 University Private, Ottawa, ON K1N 6N5, Canada

${ }^{9}$ The George Institute for Global Health, The University of Oxford, Oxford, UK Full list of author information is available at the end of the article
}

(C) The Author(s). 2020 Open Access This article is licensed under a Creative Commons Attribution 4.0 International License, which permits use, sharing, adaptation, distribution and reproduction in any medium or format, as long as you give appropriate credit to the original author(s) and the source, provide a link to the Creative Commons licence, and indicate if changes were made. The images or other third party material in this article are included in the article's Creative Commons licence, unless indicated otherwise in a credit line to the material. If material is not included in the article's Creative Commons licence and your intended use is not permitted by statutory regulation or exceeds the permitted use, you will need to obtain permission directly from the copyright holder. To view a copy of this licence, visit http://creativecommons.org/licenses/by/4.0/. The Creative Commons Public Domain Dedication waiver (http://creativecommons.org/publicdomain/zero/1.0/) applies to the data made available in this article, unless otherwise stated in a credit line to the data. 


\section{Background}

Although maternal mortality declined from 451,000 in 2000 to 295,000 in 2017, more than 800 women still die globally each day from pregnancy and childbirth-related complications [1]. Approximately 20 other women undergo disabilities, severe injuries or infections for each maternal death. Globally, sub-Saharan Africa accounts for over two thirds $(68 \%)$ of all maternal deaths every year, which is roughly 533 maternal deaths per 100,000 live births, or 200,000 maternal deaths a year [1]. Although there was a drop of 58.9 deaths per 100, 000 live births in the maternal mortality ratio (MMR) in Angola between 1990 and 2015, the MMR was 477 deaths per 100,000 live births at the end of the 2015 Millennium Development Goals [2].

Antenatal care (ANC) is the health care provided by a skilled professional during pregnancy [3]. ANC coverage is a measure of access and utilization of health care during pregnancy [4]. It provides an opportunity for pregnant women to use services that contribute to a "positive pregnancy experience" [3]. ANC coverage remains an essential indicator of access and use of health care during pregnancy; it is measured as the number of women aged 15-49 with a live birth in a given period that received ANC, four or more times during pregnancy, as a percentage of the women aged 15-49 who had a live birth in the same period [5]. Numerous studies have shown positive effects of antenatal care on infant birth weight $[6,7]$, early detection of diseases or risks and fetal abnormalities including the diagnosis of growth retardation [8-10] and reductions in maternal and neonatal morbidity and mortality $[11,12]$.

Studies conducted by a number of scholars in Africa have identified socio-economic factors such as maternal education, household wealth status, sub-national region, and place of residence as predictors of the utilization of ANC services [13-19]. Literature in Angola show maternal health service, including ANC, can be affected by socio-economic factors such as maternal education, maternal age, household economic status, place of residence, distance to facility, parity and previous adverse pregnancy outcomes [20, 21].

Monitoring the status of inequality, both across and within countries, identifies the prevalence of inequality in various facets of health and considers priority areas for further research. Policies, programmes and practices should ensure equity by improving the lives of the most disadvantaged subgroup(s). Without a dedicated focus of the investments, initiatives may lead to an increase in national coverage but the risk remains in intensifying inequality within the country as inequities among the sub-groups are not addressed [22]. Maternal health disparities have been key issues across [23] and within countries [24, 25]. A study in low-and middle-income countries (LMICs) shows ANC coverage of at least four visits differed by 27 percentage points between women who attended secondary school and above and noneducated women [26]. Furthermore, ANC coverage of at least one visit different by nearly 11 percentage points between richest and poorest women in half of the studied countries [26].

There is little evidence in Angola about determinants of utilization of ANC services $[20,21]$ and the extent of socio-economic and geographically related inequalities are largely unknown. Context-based evidence is necessary to provide targeted interventions that reduce health inequities among sub-groups [27]. Therefore, this study determined the magnitude of socio-economic, urbanrural and regional disparities in Angola using the rigorous inequality measuring techniques, the Health Equity Assessment Toolkit, developed by the WHO. Findings from the study will contribute to literature on inequalities in maternal healthcare services utilization in lowand middle-income countries and toward the attainment of universal health coverage as defined in the Sustainable Development Goals.

\section{Methods}

Study area

Angola is a vast country with a total population of more than 30.8 million (2018) [28]. Despite substantial progress on macro-economic constancy and fundamental improvements, Angola is still downgraded by the effects of decreased oil fees and an estimated reduction in gross domestic product (GDP) of about 1.2\% in 2018 [28]. Oil accounts for one-third of the GDP and more than $90 \%$ of exports in the country [28]. Angola is ranked number 147 out of 189 countries in the Human Development Index despite its vast oil wealth and high per capita GDP. This implies medium scores in the education and health sectors of the economy and scores above the average of 0.541 for countries in Sub-Saharan Africa [29]. Much of the population is living in poverty, and the country could benefit from more inclusive development policies as the government establishes a social protection system program intended to support deprived societies [28].

Angola's health system comprises of two major divisions, primary health with a community-level preventative service, and acute care with hospital services for complex treatments. According to the 2017 UNICEF report, the country has also been affected by various disasters such as cholera outbreaks, floods and a refugee inflow from the Democratic Republic of the Congo, while continuing to fight against the effects of the El Niño-induced droughts and the yellow fever outbreak [30].

\section{Data source}

We used data from the 2015-2016 Angola Nationally representative Multiple Indicator and Health Survey 
(IIMS). This is the fourth Multiple Indicator Cluster Survey and the first Demographic and Health Survey for the country. It aimed to provide a profile of the country's demographic and health situation regarding maternal and child health, fertility, family planning status, malaria, HIV/AIDS, and domestic violence [21]. A total of 14,379 women aged 15-49 in 16,109 households and 5684 men aged 15-54 in half of the selected households were interviewed in the 2015-2016 IIMS. This represented a response rate of $96 \%$ for women and $94 \%$ for men. The sample design for the 2015-16 IIMS provided national and regional as well as rural-urban estimates [21]. Detailed information on study design (i.e. sample weights to account for stratified survey design used by the DHS) are available in the survey and the details of how the WHO accounted for this in the HEAT Software can be found in the HEAT technical document [31].

\section{Selection of variables}

ANC includes the number of antenatal care visits completed by a pregnant woman. In this study, inequality was measured for ANC coverage, where the woman received antenatal care at least four times during her last pregnancy. Although WHO has recently made new recommendations that the minimum number of antenatal visits should be eight [3], we used the previous WHO ANC visit recommendation and coverage definition of at least four ANC visits as a benchmark for a pregnant woman to be deemed protected from pregnancy-related risk and complications [32]. This article will refer to the 'at least four visit model' as ANC from hereon in.

\section{Measures}

We measured inequality of ANC coverage using four equality stratifiers namely, economic status, educational status, place of residence and subnational region. Economic status was approximated by wealth index computed based on household assets and characteristics of the household. In DHS, wealth index is computed using Principal Component Analysis (PCA) [33]. It is classified as poorest, poor, middle, rich and richest. Educational status of the mother was categorized as no education, primary and secondary or higher education. Residence was classified as urban and rural. Subnational region was grouped into 18 regions for which the data was collected.

\section{Statistical analysis}

Inequality in ANC coverage was disaggregated by four equity stratifiers (economic status, education status, place of residence and subnational region). Disparity was examined using the inequality summary measures of Difference, Population Attributable Risk (PAR), Population Attributable Fraction (PAF) and Ratio. While Difference and Ratio are simple measures, the remaining two are complex measures. Relative inequalities were measured by Ratio and PAF, whereas, the absolute inequalities were by Difference and PAR. By considering previous recommendation of using relative and absolute as well as single and complex measures in a single study, our selection of summary measures complied with and used all recommendations [22]. The significance of this approach is that each inequality summary measure could lead to different, even contradictory conclusions [22], and reduce bias in the decision-making process. Unlike simple measures, they consider the size of categories of a subpopulation and are preferred when a population shift has possibly occurred [22]. Simple measures are easy for explanation, interpretation and understanding. Hence, an inequality study should comprise both simple and complex, as well as relative and absolute measures to provide a more comprehensive view for decision-makers.

The 2019 updated version of the 3.1 WHO's Health Equity Assessment Toolkit (HEAT) software was used for the analysis [31]. Detailed procedures and calculation of summary measures are available in the HEAT software (31, and in the WHO handbook on health inequality monitoring [22]. But briefly, Difference (D) was calculated for economic status (richest group minus poorest group), education (secondary or higher educated group minus uneducated group), place of residence (urban minus rural) and subnational region (the region with highest ANC 4 coverage minus region with lowest ANC 4 coverage). Ratio (R) was calculated by dividing the two subgroups mentioned for each dimension to render a relative value. Inequality did not exist if $D$ had a value of 0 or $R$ had a value of 1 .

PAR was also calculated by subtracting ANC coverage of the national average from the reference group. The reference group for economic status, education status and place of residence were richest, secondary school or higher and urban residence, respectively. For the subnational region, the reference group was the region with highest ANC estimate (Luanda). PAF is calculated by dividing PAR by the national average $(\mu)$ and multiplying by 100 . A PAR or PAF value of zero indicated the absence of inequality and the greater absolute value of both complex measures indicated higher inequality favouring the advantaged subgroups. To examine whether ANC service demonstrates statistically significant inequalities across the sub-populations of each equity stratifier, we computed 95\% Uncertainty Intervals (UI) around point estimates of each measure. For inequality measures of D, PAF and PAR, the lower and upper bounds of the UI must not include zero to interpret that inequality exists. For Ratio, the interval should not include one.

\section{Ethical consideration}

From publicly available DHS data set, data analysis were performed. Because the ethical clearance was approved 
by the institution that commissioned, funded and managed the overall DHS program, further ethical clearance was not required. Informed consent from the participants before survey was ensured by those responsible for survey deployment. The ICF International and respective country's ethical review board (IRB) also ensured that the protocols follow the U.S. Department of Health and Human Services regulations for the protection of human subjects.

\section{Results}

In this study, a total of 8492 study participants were surveyed. Approximately 3046 (35.8\%) were rural residents, more than one-fourth $(26.8 \%)$ were non-educated, 3219 (37.9\%) had primary school education and 2995 (35.2\%) had attended a secondary school or higher. Regarding economic status, nearly one-fifth (19.7\%) of the participants were from wealth quintile one (poorest) whereas, 1869 (22\%), 1707(20.1\%) and 1422 (16.7\%) belonged to poorer, rich and richest subpopulations, respectively.

Table 1 shows the difference in ANC coverage across socio-economic and regional subpopulations in 2015 in Angola, with lower coverage among disadvantaged subgroups such as poorest, non-educated, rural residents, and those living in regions like Cuanza Sul.

Coverage varied considerably across wealth quintiles. For instance, in the richest subpopulation, ANC coverage was greater as compared to the rich and middle quintile. Similarly, compared to the poorest quintile, the middle and poorer populations had better coverage (Fig. 1).

Figure 2 illustrates better coverage among subpopulations with secondary school education or higher compared to those with no formal education and primary school education.

The results also show a difference in ANC coverage across the urban-rural subpopulation. In 2015, urban residents in Angola utilized ANC services more than rural residents (Fig. 3).

There was variation in subnational regions a well. In Luanda and Zaire regions, greater ANC coverage was observed whereas, other regions such as Cuanza Sul, Mexico and Lunda Norte had lower utilization of ANC (Fig. 4).

\section{Magnitude of inequalities}

Table 2 shows profound socio-economic, regional and urban-rural disparities in ANC service utilization in 2015 favouring advantaged subpopulations. More specifically, we looked at substantial absolute and relative wealth-driven disparities in ANC service utilization both by simple $(\mathrm{D}, \mathrm{R})$ and complex (PAR, PAF) measures in 2015. The Difference measure $54.2 \%$ (95\% UI; 49.59 , 58.70) and PAF measure 43.5\% (95\% UI; 40.12, 46.92) indicated significant absolute and relative disparities
Table 1 Coverage of ANC across subnational region, socioeconomic and urban-rural subpopulations: Evidence from 2015 Angola demographic and health survey

\begin{tabular}{|c|c|c|}
\hline Subgroup & Estimate (95\% UI) & Population \\
\hline \multicolumn{3}{|l|}{ Economic status } \\
\hline Quintile 1 (poorest) & $34.03(30.44,37.82)$ & 1674 \\
\hline Quintile 2 & $44.82(41.81,47.87)$ & 1869 \\
\hline Quintile 3 & $63.99(60.98,66.89)$ & 1820 \\
\hline Quintile 4 & $81.52(77.82,84.72)$ & 1707 \\
\hline Quintile 5 (richest) & $88.18(85.23,90.61)$ & 1422 \\
\hline \multicolumn{3}{|l|}{ Education status } \\
\hline No education & $37.92(34.94,41.00)$ & 2278 \\
\hline Primary school & $59.57(56.59,62.49)$ & 3219 \\
\hline Secondary school + & $81.34(79.00,83.47)$ & 2995 \\
\hline \multicolumn{3}{|l|}{ Place of residence } \\
\hline Rural & $39.41(36.37,42.53)$ & 3046 \\
\hline Urban & $73.76(71.34,76.04)$ & 5448 \\
\hline \multicolumn{3}{|l|}{ Subnational region } \\
\hline Cabinda & $63.84(55.47,71.45)$ & 191 \\
\hline Zaire & $79.64(74.09,84.26)$ & 186 \\
\hline Uige & $38.06(30.22,46.58)$ & 460 \\
\hline Luanda & $83.23(79.43,86.44)$ & 2696 \\
\hline Cuanza norte & $53.00(43.69,62.11)$ & 111 \\
\hline Cuanza sul & $31.52(24.64,39.31)$ & 676 \\
\hline Malanje & $53.16(46.56,59.65)$ & 323 \\
\hline Lunda norte & $36.94(29.65,44.88)$ & 247 \\
\hline Benguela & $58.05(51.92,63.94)$ & 754 \\
\hline Huambo & $65.41(59.88,70.54)$ & 650 \\
\hline Bie & $49.15(42.16,56.18)$ & 414 \\
\hline Moxico & $36.65(29.80,44.08)$ & 167 \\
\hline Cuando Cubango & $41.40(33.99,49.22)$ & 164 \\
\hline Namibe & $67.77(58.95,75.48)$ & 108 \\
\hline Huila & $48.24(41.68,54.87)$ & 763 \\
\hline Cunene & $61.06(55.30,66.52)$ & 321 \\
\hline Lunda sul & $60.11(54.37,65.59)$ & 163 \\
\hline Bengo & $64.78(54.64,73.73)$ & 92 \\
\hline National average & 61.4464 & 8492 \\
\hline
\end{tabular}

respectively, favouring advantaged subpopulation such as richest and rich as compared to poorest and poor subpopulations. It means ANC coverage among the richest women was higher by 54 percentage points (pp) as compared to the poorest. Additionally, the utilization among the richest women was 2.6 times higher than the poorest. If the country had avoided both the absolute and relative wealth-related disparities, the 2015 national ANC coverage could be increased by an estimated 26.7 pp. (PAR), and 43.5 pp. (PAF), respectively. 


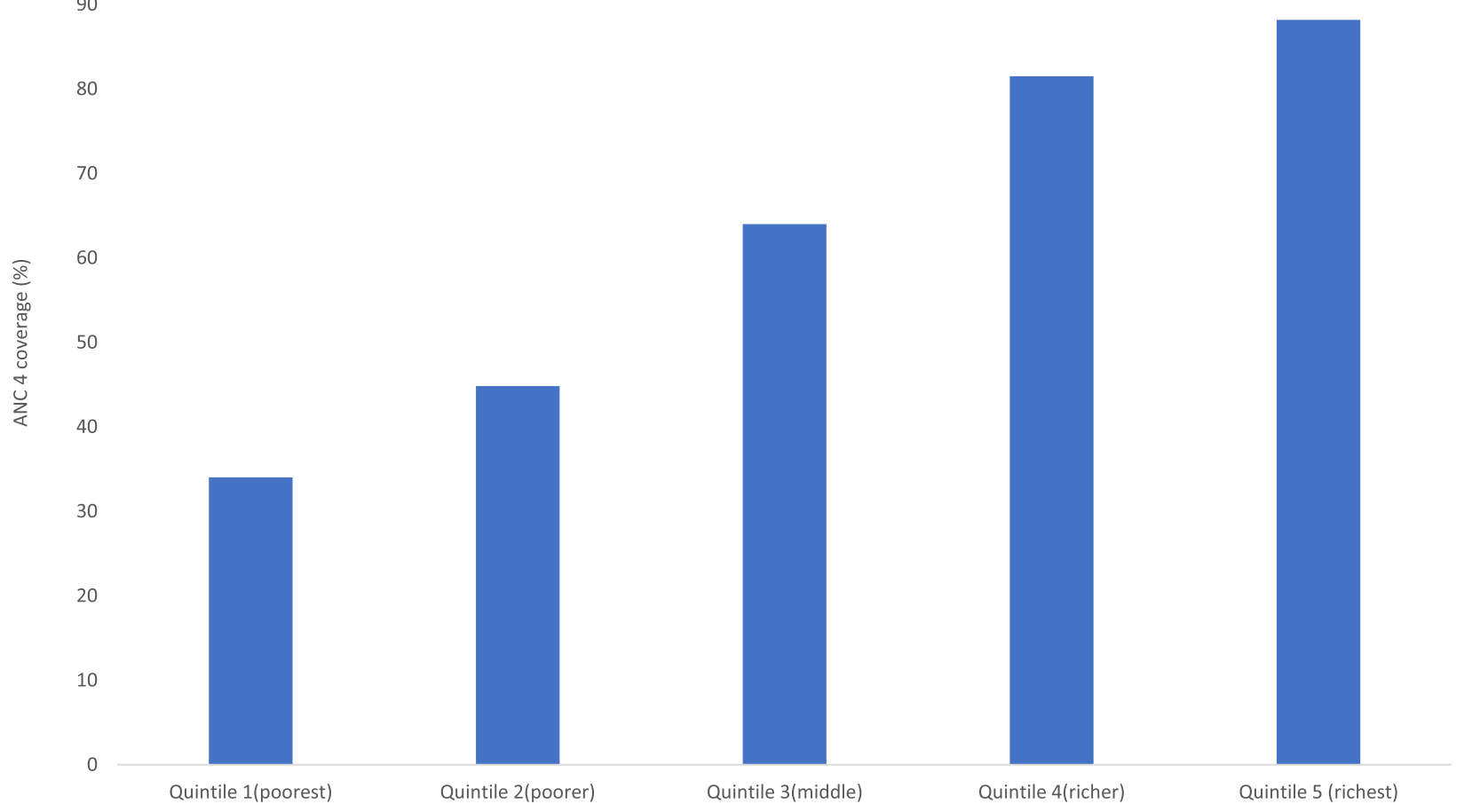

Fig. 1 Coverage of ANC services across wealth quintiles in Angola: Evidence from 2015 Angola demographic and health survey

Broad absolute and relative education-related inequalities in ANC coverage were observed using all measures (D, PAR, PAF, R) not favouring the disadvantaged subpopulation. The Ratio measure of 2.1 (95\% UI; 1.96, 2.32) and the PAR measure of 19.9 (95\% UI; 18.14, 21.64) indicate significant relative and absolute disparities with disproportionately lower ANC coverage among non-educated and primary school educated subgroups compared to the secondary school or higher educated subgroup. For instance, we found a disproportionately 43.4 pp. excess ANC coverage among women who had had secondary school and above levels of education as compared to women who had no formal education. The findings also showed that the 2015 ANC national coverage could have been improved by an estimated 32.4 pp. (PAF) or 19.9 pp. (PAR) if the country had no education-related inequalities among the subgroups.

Pro-urban disparities in ANC service utilization were also observed. The PAF measure of $20 \%$ (95\% UI; 17.70 , 22.38) and the PAR measure of $12.3 \%$ (95\% UI; 10.88 , 13.75), revealed significant absolute and relative urbanrural disparities in ANC service utilization, favouring the urban residents. Pregnant women who lived in urban settings utilized ANC services 1.8 times (95\% UI; 1.71, 2.02) more than rural residents. If the country evaded absolute and relative urban-rural disparities, the 2015
ANC coverage could be improved by $12.3 \mathrm{pp}$. (PAR) and 20.04 pp. (PAF).

We noticed significant subnational region inequalities in ANC service utilization both by simple (D, R) and complex (PAF, PAR) measures favouring subpopulation in regions like Luanda and Zaire. For instance, coverage among women living in the Luanda region was $51.7 \mathrm{pp}$. higher than in Cuanza Sul region. More specifically, the utilization in Luanda region was 2.6 times higher as compared to Cuanza Sul region. The 2015 ANC coverage could be increased by $35.5 \mathrm{pp}$. and $21.8 \mathrm{pp}$. if the country had cut the relative (PAF) and absolute (PAR) regional variation, respectively (Table 2 ).

\section{Discussion}

Roughly 810 maternal deaths occur every day as a result of preventable pregnancy and childbirth-related causes, and $94 \%$ of these deaths occur in low-and lower-middleincome countries [34] . Even though ANC service plays a crucial role in averting the preventable maternal mortality, socio-economic inequalities still hinder many mothers from using the service [15-19].

To the best of our knowledge, this is the first study to assess inequalities in the use of ANC services in Angola using standardized methods to stratify the health inequalities. We found socio-economic, urban-rural and 


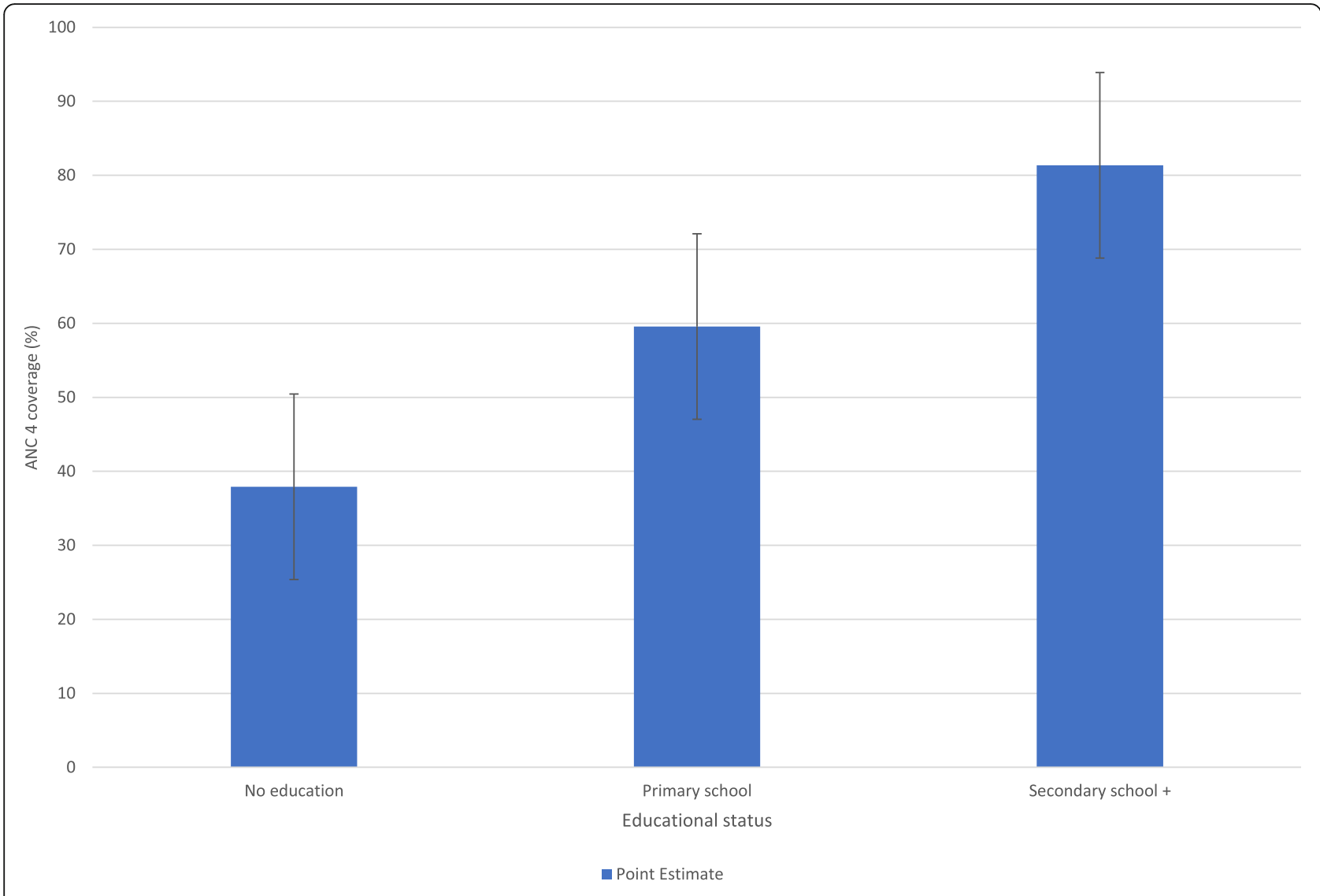

Fig. 2 ANC service coverage based on maternal educational level in Angola: Evidence from 2015 Angola demographic and health survey

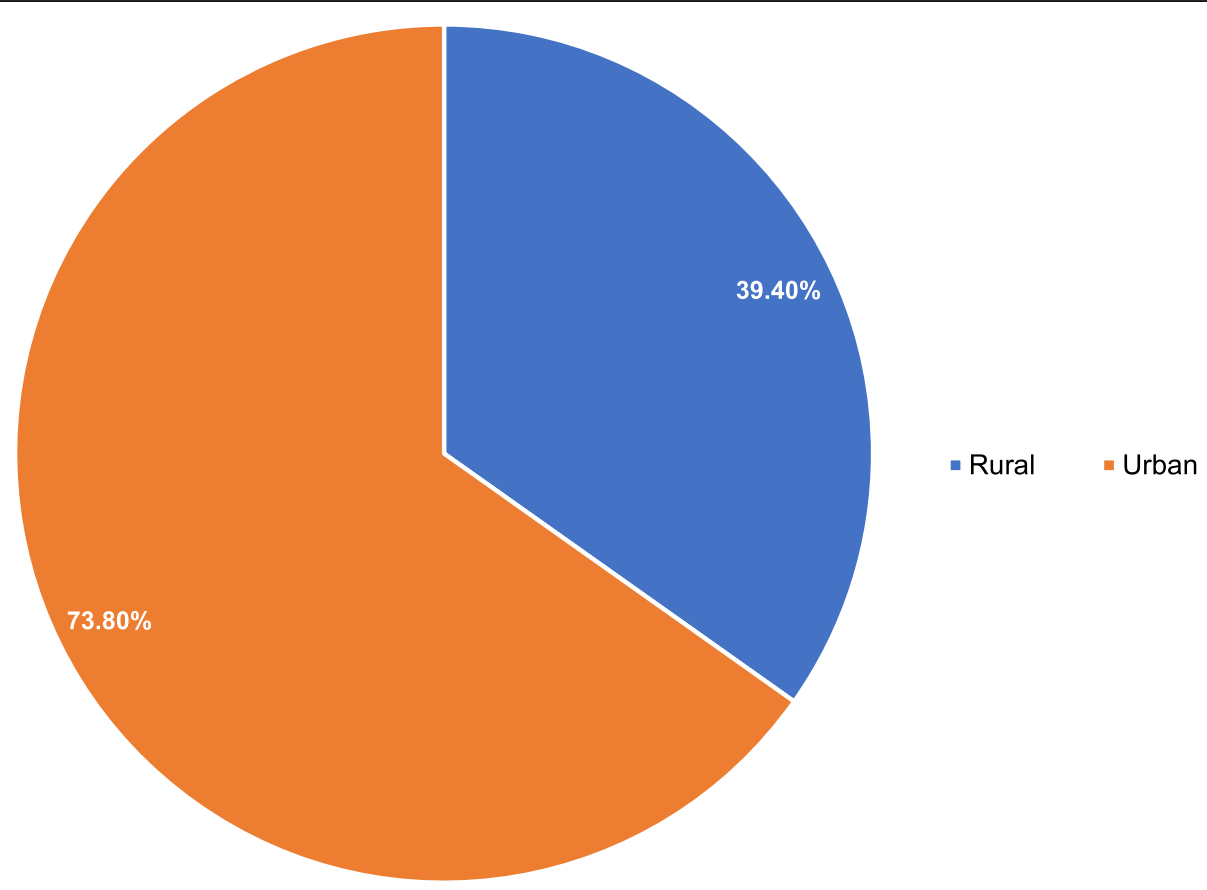

Fig. 3 ANC coverage among urban-rural subpopulation in Angola: Evidence from 2015 Angola demographic and health survey 


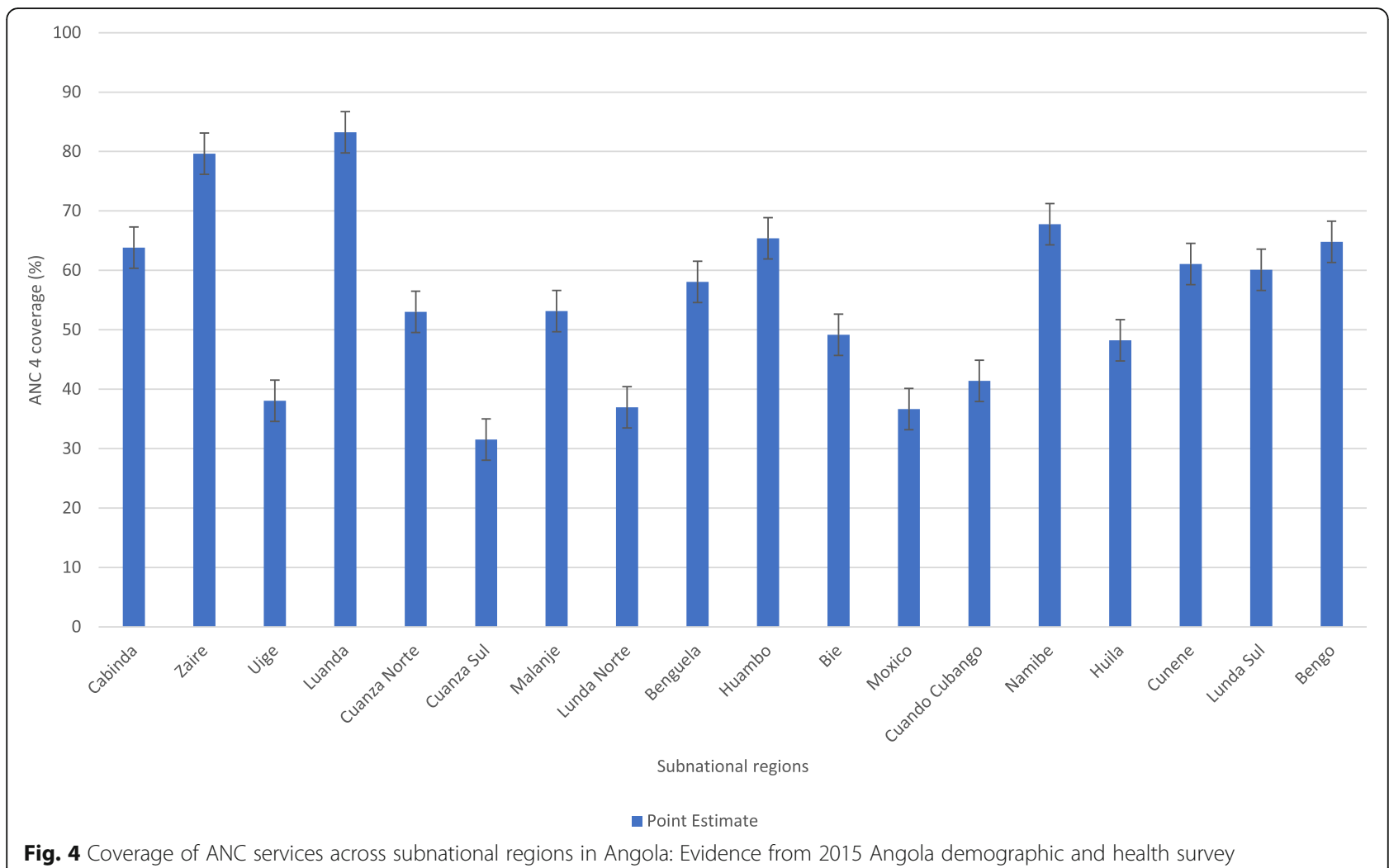

Table 2 Regional variation and socio-economic inequalities in ANC coverage: Evidence from 2015 Angola demographic and health survey

\begin{tabular}{lll}
\hline Dimensions of inequality & Summary measures & Estimate $[95 \%$ UI \\
\hline Economic status & D & $54.15(49.59,58.70)$ \\
& PAF & $43.52(40.12,46.92)$ \\
& PAR & $26.74(24.65,28.83)$ \\
Education & R & $2.59(2.29,2.88)$ \\
& D & $43.41(39.65,47.17)$ \\
& PAF & $32.38(29.53,35.23)$ \\
Place of residence & PAR & $19.89(18.14,21.64)$ \\
& R & $2.14(1.96,2.32)$ \\
& D & $34.35(30.47,38.22)$ \\
& PAF & $20.04(17.70,22.38)$ \\
& PAR & $12.31(10.88,13.75)$ \\
Subnational region & R & $1.87(1.71,2.02)$ \\
& D & $51.70(43.56,59.85)$ \\
& PAF & $35.45(29.91,40.99)$ \\
& PAR & $21.78(18.38,25.18)$ \\
& R & $2.64(2.01,3.26)$ \\
\hline
\end{tabular}

regional disparities with greater use of ANC services among pregnant women who were rich, educated, residing in urban settings and in regions like Luanda. These findings have provided an elaborate understanding of the coverage and magnitude of socio-economic, urbanrural and regional inequalities in the use of ANC in Angola. The novelty of these findings lies in their contribution to the contextual understanding of disparities in access to maternal healthcare in the midst of governmental policies to improve healthcare access.

Consistent with available literature [19, 35], we noticed extensive pro-rich disparities in the utilization of ANC services in Angola. The logical explanation for better ANC uptake among rich/richest women could be that women in the lower wealth quintiles (poorer or poorest) may not be able to afford the medical and non-medical costs associated with using ANC [36, 37]. Financial challenges may prevent poor women from attending ANC at all, limit the number of ANC visits or prolong the timing of ANC. The effects of socioeconomic status on the use of ANC services have been documented in other studies $[37,38]$. Despite the presence of free (or subsidized) maternal health services for women in some African countries, women still bear some direct out of pocket medical costs (i.e. laboratory testing) and non-medical costs (i.e. transportation), posing financial barriers to the use of ANC services [39, 40]. Additionally, utilization, 
early timing of ANC visits and attendance at the recommended number of ANC visits are reduced in women who do not have health insurance [41]. Women's desire to use ANC services during pregnancy is also hindered by their inability to pay for the services due to their lowincome status $[41,42]$.

Similar to previous studies, our findings have shown a higher utilization of ANC services by educated women compared to women with no formal education in Angola [43, 44] Evidence suggest that health knowledge remains the important factor that explains the observed association between higher level of maternal education and use of maternal health care services including ANC [45]. The evidence further asserts that as a woman acquires more accurate information about a wide range of information on different health topics, she is more likely to use maternal health services. We have seen better ANC services usage among urban residents in Angola. Other studies have also identified the effect of urban residence on the use of ANC services [46, 47]. This might be explained by women in rural settings having to traverse long distances before receiving maternal health services [48]. Further, lack of transport, user fees, poorly staffed and ill-equipped institutions with poorly skilled personnel are problematic for women living in rural areas [48].

In our study, we found significant regional variation in ANC uptake across several regions in Angola. Our findings are comparable to the available evidence [43]. The reasonable explanation is the difference in remoteness, road and transport access, accessibility of health facilities, skilled health personnel and quality of care in the health care facilities [49].

These findings have provided an understanding of the need to ensure the effective implementation of the Angola National Health strategy 2016 which seeks to guarantee the provision of an essential health care package, mobilize communities, strengthen partnerships and promote health to ensure access to primary health care for the entire population by strengthening the municipal health system [50]. These socio-economic, rural-urban and subnational level disparities in access to ANC contradict the vision of Angola's National Health Development Plan 2012-2025 which aims, among other things, to reduce maternal and child mortality through access to healthcare for all mothers [50]. Therefore, there is a need for the implementers of this Health Development Plan to revisit the aims, objectives and activities guiding the Health Development Plan to ensure that it considers the needs of disadvantaged groups in terms of healthcare access.

\section{Strengths and limitations}

The study has a few strengths. First, inequality in ANC service utilization was examined using the
WHO recommended Health Equity Assessment toolkit, which comprises various summary measures of the same phenomenon to assess inequality of different dimensions. This method has the potential to provide policymakers with multiple perspectives; consequently, it avoids the implementation of evidence-based strategies generated by a single or two summary measure that looks at average national-level data. Secondly, the study used the established WHO Health Equity Monitor Database (HEMD), which houses data from the Demographic Health Surveys, Multiple Indicator Cluster Surveys, and Reproductive Health Surveys from 112 countries. Using this HEMD allows comparable results to other published work based on the same source. There are also limitations in the study. We do not make any attempt to delve into the underlying causes of the observed ANC utilization disparities; we suggest future studies to explore factors that could explain the inequalities in the use of ANC services across different equity stratifiers. This can be done by utilizing different statistical approaches which would create models (i.e. regression analysis, decomposition analysis) to explore factors (i.e. distance to health facility \& insurance) that explain the inequalities in the use of ANC services across equity stratifiers in Angola.

\section{Conclusion}

Disparities in the use of ANC services have been to the detriment of poor and uneducated women, as well as women residing in rural areas or specific regions of Angola. Our findings have also shown the extent of the current disparity status using a variety of summary measures. We firmly recommend the need to improve upon the implementation of maternal healthcare policies that function best in the context of disadvantaged subpopulations to improve the utilization of ANC services. Such policies should include interventions aimed at strengthening media coverage to motivate mothers to access ANC services regardless of their wealth status, level of education or place of residence. To meet the needs of socio-economically disadvantaged women, community-based information centres can also be used as modes of providing education on ANC. Additionally, efforts should focus on training and motivating community health volunteers to provide home visits, counselling and identify mothers who require special ANC care. This can be enhanced through referrals to the next level health facility. All these policy interventions can help meet the 2030 Sustainable Development Goal (SDG) and reduce maternal mortality ratio (MMR) to $70 / 100$, 000 live births. Further studies are essential to investigate underlying layers of inequities that lead to ANC inequality; especially for developing nations like Angola to be able to overcome the problems at a low cost. 


\section{Abbreviations}

ANC: Antenatal Care; UI: Uncertainty Interval; D: Difference;

DHS: Demographic and Health Survey; EA: Enumeration Area; EDHS: Ethiopia Demographic and Health Survey; HEAT: Health Equity Assessment Toolkit: ICF: Inner City Fund; PAR: Population Attributable Risk; PAF: Population Attributable Fraction; PCA: Principal Component Analysis; PPS: Probability Proportional to Size; R: Ratio; SDG: Sustainable Development Goal; WHO: World Health Organization

\section{Acknowledgements}

The authors thank WHO for making the HEAT software freely available to researchers.

\section{Authors' contributions}

SY, GS and BZ contributed to the conception and design of the study, interpreted the data, and prepared first draft of the manuscript. DIW, BOA and $\mathrm{OO}$ contributed to data interpretation, and revised first draft thoroughly for its intellectual content. SY had final responsibility to submit. All authors read and revised drafts of the paper and approved the final version.

\section{Funding}

No funding was received for this work.

\section{Availability of data and materials}

The datasets generated and/or analyzed during the current study are available in the WHO's HEAT version 3.1 [https://www.who.int/gho/health_ equity/assessment_toolkit/en/].

\section{Ethics approval and consent to participate}

Ethics approval was not required since the data is available to the public domain.

\section{Consent for publication}

Not applicable.

\section{Competing interests}

Bright Opoku Ahinkorah, Olanrewaju Oladimeji and Sanni Yaya are associate editors with this journal.

\section{Author details}

'Department of Reproductive, Family and Population Health, School of Public Health, Addis Ababa University, Addis Ababa, Ethiopia. ${ }^{2}$ Shewarobit Field Office, HaSET Maternal and Child Health Research Program, Addis Ababa, Ethiopia. ${ }^{3}$ Interdisciplinary School of Health Sciences, University of Ottawa, Ottawa, Canada. ${ }^{4}$ The Australian Centre for Public and Population Health Research, Faculty of Health, University of Technology Sydney, Ultimo, NSW, Australia. ${ }^{5}$ Department of Public Health, Walter Sisulu University, Mthatha, Eastern Cape, South Africa. ${ }^{6}$ Faculty of Health Sciences, Durban University of Technology, Durban, South Africa. ${ }^{7}$ Department of Family Medicine and Public Health, Faculty of Medicine, University of Botswana, Gaborone, Botswana. ${ }^{8}$ School of International Development and Global Studies, Faculty of Social Sciences, University of Ottawa, 120 University Private, Ottawa, ON K1N 6N5, Canada. ${ }^{9}$ The George Institute for Global Health, The University of Oxford, Oxford, UK.

Received: 27 May 2020 Accepted: 30 July 2020

Published online: 15 August 2020

\section{References}

1. UNICEF. Maternal Mortality. Available at https://data.unicef.org/topic/ maternal-health/maternal-mortality/. Accessed on 29 Apr 2020.

2. WHO, UNICEF, UNFPA, World Bank Group, United Nations Population Division. Trends in maternal mortality: 1990 to 2015. In: Estimates by WHO, UNICEF, UNFPA, World Bank Group and the United Nations population division. Geneva: World Health Organization; 2016.

3. WHO. WHO Recommendations on Antenatal Care for a Positive Pregnancy Experience. Geneva: WHO; 2016. Available from: https://www.ncbi.nIm.nih. gov/books/NBK409110/. Accessed on 20 July 2020.

4. WHO. Antenatal care coverage. Available at: https:/www.who.int/whosis/ whostat2006AntenatalCareCoverage.pdf. Accessed on 29 Apr 2020.
5. World Health Organization. World health statistics 2015: indicator compendium. Geneva: World Health Organization; 2015.

6. Habibov NN, Fan L. Does prenatal healthcare improve child birthweight outcomes in Azerbaijan? Results of the national demographic and health survey. Econ Hum Biol. 2011;9(1):56-65.

7. Zhou H, Wang A, Huang X, Guo S, Yang Y, et al. Quality antenatal care protects against low birth weight in 42 poor counties of Western China. PLoS One. 2019;14(1):e0210393.

8. Grande M, Arigita M, Borobio V, Jimenez JM, Fernandez S, Borrell A. Firsttrimester detection of structural abnormalities and the role of aneuploidy markers. Ultrasound Obstet Gynecol. 2012;39(2):157-63. https://doi.org/10. 1002/uog.10070.

9. Palomaki GE, Haddow JE, Beauregard L. Prenatal screening for Down's syndrome in Maine, 1980 to 1993. N Engl J Med. 1996;334(21):1409-10.

10. Backe B, Consultant JN. Effectiveness of antenatal care: a population based study. BJOG Int J Obstet Gynaecol. 1993;100(8):727-32.

11. Linard M, Blondel B, Estellat C, Deneux-Tharaux C, Luton D, Oury J, et al. Association between inadequate antenatal care utilisation and severe perinatal and maternal morbidity: an analysis in the pre CARE cohort. BJOG Int J Obstet Gynaecol. 2018;125(5):587-95.

12. Arunda M, Emmelin A, Asamoah BO. Effectiveness of antenatal care services in reducing neonatal mortality in Kenya: analysis of national survey data. Glob Health Action. 2017;10(1):1328796. https://doi.org/10.1080/16549716. 2017.1328796.

13. Shibre G, Mekonnen W. Socio-economic inequalities in ANC attendance among mothers who gave birth in the past 12 months in Debre Brehan town and surrounding rural areas, North East Ethiopia: a community-based survey. Reprod Health. 2019;16:99. https://doi.org/10.1186/s12978-019-0768-8.

14. Arthur E. Wealth and antenatal care use: implications for maternal health care utilization in Ghana. Heal Econ Rev. 2012;2(1):14.

15. Mezmur M, Navaneetham K, Letamo G, Bariagaber H. Socioeconomic inequalities in the uptake of maternal healthcare services in Ethiopia. BMC Health Serv Res. 2017;17:367.

16. Gebre E, Worku A, Bukola F. Inequities in maternal health services utilization in Ethiopia 2000-2016: magnitude, trends, and determinants. Reprod Health. 2018:15(1):119.

17. Goli S, Nawal D, Rammohan A, Sekher TV, Singh D. Decomposing the socioeconomic inequality in utilization of maternal health care services in selected countries of South Asia and sub-Saharan Africa. J Biosoc Sci. 2018; 50(6):749-69. https://doi.org/10.1017/50021932017000530.

18. Alam N, Hajizadeh M, Dumont A, Fournier P. Inequalities in maternal health care utilization in sub-Saharan African countries: a multiyear and multicountry analysis. PLoS One. 2015;10(4):e0120922.

19. Yaya S, Uthman OA, Amouzou A, Ekholuenetale M, Bishwajit G. Inequalities in maternal health care utilization in Benin: a population based crosssectional study. BMC Pregnancy Childbirth. 2018;18(1):194.

20. Rosário EVN, Gomes MC, Brito M, Costa D. Determinants of maternal health care and birth outcome in the Dande health and demographic surveillance system area, Angola. PLoS One. 2019;14(8):e0221280. https://doi.org/10. 1371/journal.pone.0221280.

21. Instituto Nacional de Estatística - INE/Angola, Ministério da Saúde - MINSA/ Angola, Ministério do Planeamento e do Desenvolvimento Territorial (MINP LAN) and ICF. Inquérito de Indicadores Múltiplos e de Saúde em Angola 2015-2016. Luanda, e Rockville: EUA: INE, MINSA, MINPLAN and ICF; 2017.

22. WHO. Handbook on health inequality monitoring: with a special focus on low-and middle-income countries. Geneva: World Health Organization; 2013. p. 105.

23. Yaya S, Ghose B. Global inequality in maternal health Care service utilization: implications for sustainable development goals. Health Equity. 2019;3(1): 145-54. https://doi.org/10.1089/heq.2018.0082.

24. Zhang R, Li S, Li C, Zhao D, Guo L, et al. Socioeconomic inequalities and determinants of maternal health services in Shaanxi Province, Western China. PLoS One. 2018;13(9):e0202129. https://doi.org/10.1371/journal.pone. 0202129.

25. Ali B, Chauhan $\mathrm{S}$. Inequalities in the utilisation of maternal health Care in Rural India: Evidences from National Family Health Survey III \& IV. BMC Public Health. 2020;20:369. https://doi.org/10.1186/s12889-020-08480-4.

26. World Health Organization. State of Inequality. Reproductive, maternal, newborn and child health: WHO; 2015. Available from: World Health Organization. State of Inequality. Reproductive, maternal, newborn and child health. Accessed on 20 July 2020. 
27. $\mathrm{CSDH}$. Closing the gap in a generation: health equity through action on the social determinants of health. In: Final report of the commission on social determinants of health. Geneva: World Health Organization; 2008.

28. World Bank. The World Bank in Angola. 2019. Available from https://www. worldbank.org/en/country/angola/overview. Accessed on 09 May 2020.

29. UNDP. Human Development Report 2019. Inequalities in Human Development in the 21st Century Briefing note for countries on the 2019 Human Development Report. Angola. Available from: https://www.ao.undp. org/content/dam/angola/docs/Publications/HDR\%202019_Angola.pdf. Accessed 09 May 2020.

30. UNICEF. UNICEF Angola Situation Report. Angola humanitarian situation Report. 2017.

31. Health Equity Assessment Toolkit (HEAT). Software for exploring and comparing health inequalities in countries. In: Built-in database edition. Version 3.1. Geneva: World Health Organization; 2019.

32. World Health Organization (WHO). Mother-baby package: implementing safe motherhood in countries: practical guide. Geneva: Maternal Health and Safe Motherhood Programme, Division of Family Health. World Health Organization; 1996.

33. Rutstein SO and Johnson K. The DHS wealth index. http://www.measuredhs. com/pubs/pdf/CR6/CR6.pdf. Accessed on 23 Nov 2019.

34. World Health Organization. Maternal mortality. Factsheets, 2019. Available from: https://www.who.int/news-room/fact-sheets/detail/maternal-mortality. Accessed on 21 July 2020.

35. Barros A, Victora C, Horta B, Wehrmeister F, Bassani D, Silveira M, et al. Antenatal care and caesarean sections: trends and inequalities in four population-based birth cohorts in Pelotas, Brazil, 1982-2015. 2020. Int J Epidemiol. 2019;48(Supplement_1):i37-45. https://doi.org/ 10.1093/ije/dyy211.

36. Titaley CR, Hunter CL, Heywood P, Dibley MJ. Why don't some women attend antenatal and postnatal care services?: a qualitative study of community members' perspectives in Garut, Sukabumi and Ciamis districts of West Java Province, Indonesia. BMC Pregnancy Childbirth. 2010;10:61. Published 2010 Oct 12. https://doi.org/10.1186/1471-2393-10-61.

37. Fagbamigbe AF, Idemudia ES. Wealth and antenatal care utilization in Nigeria: policy implications. Health Care Women Int. 2017;38(1):17-37. https://doi.org/10.1080/07399332.2016.1225743.

38. Arthur E. Wealth and antenatal care use: implications for maternal health care utilisation in Ghana. Heal Econ Rev. 2012;2:14. https://doi.org/10.1186/ 2191-1991-2-14.

39. Kalu-Umeh NN, Sambo MN, Idris SH, Kurfi AM. Costs and patterns of financing maternal health care services in rural communities in northern Nigeria: evidence for designing national fee exemption policy. Int J $\mathrm{MCH}$ AIDS. 2013;2:163-72.

40. Dalinjong PA, Wang AY, Homer CSE. Has the free maternal health policy eliminated out of pocket payments for maternal health services? Views of women, health providers and insurance managers in northern Ghana. PLoS One. 2018;13:e0184830.

41. Browne JL, Kayode GA, Arhinful D, et al. Health insurance determines antenatal, delivery and postnatal care utilisation: evidence from the Ghana demographic and health surveillance data. BMJ Open. 2016;6:e008175. https://doi.org/10.1136/bmjopen-2015-008175.

42. Prenatal Care: Chapter 2 Barriers to the Use of Prenatal Care. Reaching Mothers, Reaching Infants. Available from: https://www.ncbi.nlm.nih.gov/ books/NBK217704/. Accessed on 21 July 2020.

43. Okedo-Alex IN, Akamike IC, Ezeanosike OB, et al. Determinants of antenatal care utilisation in sub-Saharan Africa: a systematic review. BMJ Open. 2019;9: e031890. https://doi.org/10.1136/bmjopen-2019-031890.

44. Brown CA, Sohani SB, Khan K, et al. Antenatal care and perinatal outcomes in Kwale district, Kenya. BMC Pregnancy Childbirth. 2008;8:2. https://doi.org/ 10.1186/1471-2393-8-2.

45. Greenaway ES, Leon J, Baker DP. Understanding the association between maternal education and use of health services in Ghana: exploring the role of health knowledge. J Biosoc Sci. 2012;44(6):733-47. https://doi.org/10. 1017/S0021932012000041 Epub 2012 Mar 1.

46. Tekelab T, Chojenta C, Smith R, Loxton D. Factors affecting utilization of antenatal care in Ethiopia: a systematic review and meta-analysis. PLoS One. 2019;14:e0214848.

47. Chanda SK, Ahammed B, Howlader MH, Ashikuzzaman M, Shovo TEA, et al. Factors associating different antenatal care contacts of women: a crosssectional analysis of Bangladesh demographic and health survey 2014 data.
PLoS One. 2020;15(4):e0232257. https://doi.org/10.1371/journal.pone. 0232257.

48. Stekelenburg J, Kyanamina S, Mukelabai M, Wolffers I, van Roosmalen J. Waiting too long: low use of maternal health services in Kalabo, Zambia. Tropical Med Int Health. 2004;9(3):390-8. https://doi.org/10.1111/j.1365-3156. 2004.01202.x.

49. Soewondo P, Johar M, Pujisubekti R, Halimah H, Irawati DO. Inspecting Primary Healthcare Centers in Remote Areas: Facilities, Activities, and Finances. J Adm Kesehat Indones. 2019;7:89-98. https://doi.org/10.20473/ jaki.v7i1.2019.89-98.

50. World Health Organization. Regional Office for Africa. WHO country cooperation strategy 2015-2019. Angola: World Health Organization. WHO Regional Office for Africa; 2016. https://apps.who.int/iris/handle/1 0665/250515

\section{Publisher's Note}

Springer Nature remains neutral with regard to jurisdictional claims in published maps and institutional affiliations.
Ready to submit your research? Choose BMC and benefit from:

- fast, convenient online submission

- thorough peer review by experienced researchers in your field

- rapid publication on acceptance

- support for research data, including large and complex data types

- gold Open Access which fosters wider collaboration and increased citations

- maximum visibility for your research: over $100 \mathrm{M}$ website views per year

At BMC, research is always in progress.

Learn more biomedcentral.com/submissions 